\title{
Disaster Management and Community Development: A Pakistani Perspective
}

\author{
Dr. Mohammad Daud Ali \\ Assistant Professor Management Sciences \\ University of Haripur \\ dr.daud@uoh.edu.pk \\ Anwar-ul Mujahid Shah \\ Lecturer in Sociology \\ Bacha Khan University Charsadda \\ Syed Arshad Ali Shah \\ Lecturer in Management Science \\ Bacha Khan University Charsadda
}

\begin{abstract}
After making thorough on-ground observation it is observed that because of hazardous development of populace, evolving needs, financial rivalry and also inflation of the assets for social welfare administrations at the worldwide level are decreasing. Keeping in perspective the contracting position of assets for social welfare and group advancement the idea of investment rose in range of sociological areas and group improvement. Participatory approach gradually and steadily came into use in the group advancement discourse. It was trailed by a fast development in the advancement of techniques for including rustic individuals in looking at their own issues, setting their own objectives, and checking their own accomplishments. It is essential to note that an effectively included and enabled domestic populace is key for effective community development process. This paper deals with similar themes on community development and disaster management in Pakistan.It discusses the fundamental prologue to the worldview of involvement of local community; ontological transformation in disaster administration and procedure of community based disaster management in Pakistan.
\end{abstract}

Keywords: Community development, disaster management, natural calamities, group involvement, group fragility.

\section{Introduction}

Social work mediations in a debacle have concentrated on variety of means. These means include the assortment of paths that post-disaster situation influence people, families, associations and groups. Zones of matter and bothering have internalized trauma, anxiety, assets for burdened and defenseless populaces and coordination of different mediation frameworks (Zakour, 1996).Practice of disaster is seemingly an impression of the target of social work which grapple with problems (Zakour, 1996). A central and frequently dismissed component of catastrophe recuperation has been the reconstructing and group improvement stage. A survey of the writing demonstrated that welfare and rehabilitating services have been less required in any phase of 
comparison with traumatic anxiety mediation, in addition to, the interaction of supporting endeavors. Innovative academic attempts demonstrate that groups with reduced and lower rate earnings are liable to endure a descending winding of disintegration after a debacle which will sustain the results of disaster management efforts in the long run (Morrow and Peacock, 1997). Investigation reveals that the relationship of group qualities some time recently a fiasco with the survival or disappointment after debacle of eight groups that accomplished the flood in Midwestern area of USA in 1993 (Sundet \& Mermelstein 1996). Results have been inferred that the relation between increasing need and inability of survival is direct. More need means more inability and less need means less inability. Academic research on reasons behind and effects of disaster in the neighbouring countries of China including Philippines, secular republic of Turkey and different nations exhibit comparative results (Allen, 2003; Ozerdem, 2003). Accessible and approachable approach to protected, reasonable lodging, clean situations, living-wage employments and different parts of social advancement are basic after a catastrophe for those generally powerless to longer-time impacts (Holzer 7 Lerman, 2006; Zedlewski, 2006). In spite of the fact that welfare society for amelioration of post-disaster situation is included in psychological and social mediations in debacles, the calling has given careful consideration to socio-cultural improvement in recuperation activities after disaster.

It is also contended that calamities are once in a while the outcome of uncertain advancement challenges (Ozerdem 2003: 201). He contends that 'practical advancement can lessen weakness by tending to the root reasons for fiascos and the absence of access to financial and political instruments'. Since legislative offices and urban organizers are regularly the focal performing artists in post-catastrophe revamping, it is critical for residents to be effectively occupied with these political procedures. As contribution from neighborhoods and representatively marginalized populaces is most certainly not regularly requested by intense associations, it is important to activate, in addition to, arrange groups with the point of impacting the financial improvement process and additionally the continuous recuperation endeavors.

In the aftermath of the overwhelming natural disaster of floods that took after the occurrence of Hurricane Katrina with disastrous effects throughout the New Orleans and had socio-economic impacts in August 2005, group association flourishes. People have activated around issues which affect various walks of life. These effected spheres of life include return of people to their hometowns through rehabilitation, availability of bread, clothes and roofs, planning of local residence, monetary improvement and numerous different issues fundamental to the groups which embody justice (Axel-Lute, 2006). Few of these arranging includes tending to also, changing disparities between different classes and primordial factions of society. To embrace these advancement of different forms in society, new grounded and embedded endeavors have risen, locally-situated affiliations have been renewed and countrywide and worldwide nonadministrative associations or non-governmental organizations have showed up to public attention.

The objectives of group arranging, especially neighborhood-based arranging, differ, however by and large incorporate framing bunches; achieving social justice; obtaining, keeping up or rebuilding power; creating elective foundations; and keeping up or rejuvenating neighboring localities (Fisher, 1994).

\section{Conceptualization: Disasters and Community Organization}

The writing on catastrophe reaction and recuperation underscores a few critical segments of services for the improvement of society, involving mental wellbeing and group hone. Numerous 
have expounded on the part that services for resolution of social problems have driven agonizing anxiety circumstances, so here it is an attempt to address the writings on the group parts of calamity mediation. The key zones of mediation that are group centered can be categorized. Galambos (2005) and Robards et al., (2000) mentioned first category as calamity administrative interaction. Harrell and Zakour (2000), refer to second category of incorporating casual associations in the help and recuperation phase. Third category is referred by Low et al., (2005) and McNeil et al., (2006) as the part of group evaluation in a post-disaster recuperation situation. Allen, (2003) and Victoria (2001) underlined fourth category of group based cooperation in a debacle administration. This work abridges each of these regions, underlining their significance in fiasco recuperation, while differentiating them with group association, which has been dismissed in the writing.

Robards et al. (2000) underline the significance of clearing up and precisely gauging interaction between various organizations in a debacle mediation and exploration. They characterize coordination as 'the purposeful relationship of socially perceived particular components for a regular reason'. Galambos (2005) posited that a compelling reaction to characteristic calamities ought to incorporate intercessions that fuse clinical, exploration and group association aptitudes. In any case, in the same way as other authorities on the topic in question, what she truly implies by group association is the administration furthermore, interactive mediation of the reaction. Resulting ideas of the scholar are not alluding to traditional group association that might look to influence the socio-cultural quality of expansive premised gatherings of disappointed individuals in attempt to achieve the objective of exchanging force, as explained in the convention of Alinsky (1971), for instance. While interaction of these kinds, is a basic segment of the general adequacy of alleviation endeavors, it is imperative to recognize these thoughts from organizing attempts of the groups working along the lines of citizen-mobility and citizen-inclusion in post-disaster situation to resolve social advancement issues.

A few authorities have characterized the significance of casual associations furthermore, selfimprovement systems after fiasco (Harrell \& Zakour, 2000). Casual associations are generally privately premised and overseen by those who were ready to present their free-of-cost services, and may give own improvement or shared guide. Official hierarchical systems may ignore the imperative resources that volunteers, with their variety of origins, bring. Subsequently, the consideration of grassroots furthermore, casual associations can expand residents' cooperation in a debacle reactions, especially in separated or underestimated groups (Ibid). Such an incorporation of such associations can engage and enhance access to administrations for such populaces, yet it ought not to be mistaken for deliberate endeavors to impact urban arranging forms, change approaches or face relevant government quarters.

There are a few appraisal and exploration devices that are utilized as a part of catastrophes and complex crises that join a comprehension of nearby group learning and limit building. Participatory rural appraisal (PRA) is one of the manifested examples. PRA is an activity research apparatus that includes group individuals in characterizing and attempting to tackle neighborhood concerns (Chambers, 1994). This appraisal has been especially well known among global NGOs functioning in the global south. Since the procedure can enable and prompt more grounded levels of human capital and embodied social potential in a group, it holds the capacity to advise group preparation and social advancement endeavors (Ibid). Tools like PRA are not synonymous to group uniting or social advancement effort, and number of researchers has censured it for its 
over-accentuation on localism and absence of acknowledgment of the power irregular characteristics that are in existence domestically (Mohan\& Stokke, 2000).

Different cases of group situated appraisal procedures are categorized in two categories. McNeil et al., (2006) underlines first category of group situated appraisal procedure as rapid community needs assessment. Low et al. (2005) highlights second category of the procedures as rapid ethnographic assessment procedures (REAP). Former is frequently used to evaluate general wellbeing and different needs of family units after a calamity to illuminate reaction and recuperation needs. McNeil et al. (2006) work that used an irregular examining system to study families in different areas of Mississippi after the occurrence of Hurricane Katrina. The latter, following different mechanism, utilized as a part of social advancement connections, rapid rural appraisal (RRA). These two sorts of examinations comprise of multidisciplinary research groups who use semi-organized meetings, master meetings and group center gatherings. Ethnographic methodologies give a lot of social data important for arranging purposes. As exploration is dependably an imperative instrument for group coordinators, these are methods that could play an indispensable part in a purposeful sorting out thorough probe.

Disaster management owned and carried out by a local community is known as Communitybased disaster management (CBDM). It is a persuasive model that joins the standards of group preparation and association. Its performance is based on coherent, organized and united integration of different stakeholders. CBDM is a fiasco recuperation strategy that takes care of the critical part of group mending and investment in a debacle administration (Victoria, 2001). Such strategy endeavors to rectify the top-down methodology that has neglected to meet the requirements of helpless populaces and has disregarded the potential of nearby assets and limits (Victoria, 2001). Supporters of these group based methodologies trust that these are 'appropriate components for getting a handle on the elements and multifaceted nature of powerlessness, as showed at the nearby level, for tending to helplessness in addition to, fortifying nearby limits' (Van sanctum Eynde and Veno, 1999: 171). Important components of this approach are pertinent to post-debacle group getting sorted out are categorized in the followings:

1. Inclusive and involving procedures that incorporate the most powerless individuals of society.

2. Reinforcing the limits of adjoining groups.

3. Connecting calamity and improvement issues.

4. Outcasts having a strong, encouraging and reactant part.

The logic of CBDM is absolutely compatible with a portion of the theories of conventional grassroots group sorting out: group premise; an accentuation on indigenous authority; the consideration of helpless populaces; and spotlight on strengthening (Murphy also, Cunningham, 2003). In any case, it is imperative to elucidate that there are plainly contrasts between dealing with a calamity and sorting out groups to advocate for arrangement and system changes identified with group renewal needs after a debacle. In expansion, sorting out after catastrophes must go past simply including powerless individuals and center exercises on changing the hegemonic frameworks and arrangements that propagate such unfairness, in the event that it is to address advancement issues and different imbalances.

\section{Relation Between Disaster Management and Community Development}

Ozerdem (2003) contends that calamities and impacts thereof are outcomes of a development encounters and choices, and then calamities can give new open doors for advancement. 'This requires an advancement approach that is both touchy to circumstance and ready to react by planning recreation projects to consolidate such open doors' (Ozerdem, 2003: 201). 
Inquiry of Low et al. (2005) uncovered an expansion in group mobility post - 9/11 situations. Vandeventer (2004) stresses the significance of native drove association and activity in catastrophe recuperation. Leaders of diverse origins 'originate from each stroll of life also, live in each area. As a general rule, they don't keep running for office or with high open outlook (Vandeventer, 2004: 3). Whatever degree social laborers have been included in sorting out. There are variety of drivers which determine why welfare services have not contributed essentially to post-catastrophe social advancement and association. In the first place, group sorting out in social advancement issues may include centered consideration on large scale level wonders, for example, lodging approach, urban arranging and financial advancement. Their later notable spotlight on small scale level issues implies social laborers are as it were once in a while arranged to resolve such problems (Specht \& Courtney, 1996).

The second driver can be explained in the way that despite compartments and relevant aspects of social work that offer fixations in group cohesion, educational activities on social work and relevant themes are vigorously centered around conventional human conduct hypotheses, mental wellbeing and hierarchical organization. Social work instruction would require to concentrate a greater amount of its assets and consideration on groups also, their necessities, strategy backing and the gathering work abilities that are important to construct grassroots associations.

Thirdly, people group arranging includes activating abused public electorate, indigenous initiative of global south and, as Alinsky (1971) contended, sorting out 'yourself out of a vocation'. Social laborers are definitely not for the most part keen on making themselves excess. A variable contributing to this is absolutely the truth of what is financially supportable and doable movement. Giving the guidance of post-disaster situation, incorporating efforts with injury in addition to, misery, is for the most part given need since this is the place cash is accessible. It can be hard to find subsidy to sort out persecuted groups around group advancement problems.

\section{Community Development and Disaster Management in Pakistan:}

Community has a vital part to play in disaster management and reinforcing its general framework also, structures. In spite of the fact that, there is an overall expansive accord on set up standards, furthermore, procedures for community based disaster management (CBDM), distinctive nations, in any case, have created community based disaster management systems and rules as indicated by their own particular national needs and specific group and social requirements. In countries situated in global south like Pakistan, national and global NGOs have to a great extent been executing CBDM projects and exercises as indicated by their own comprehension of domestic setting. Without a national CBDM system, it gets to be problematic to make collaborations and get most extreme contents groups from CBDM endeavors. In this manner, a countrywide CBDM structure that could be further adjusted and scrutinized at common and region levels must be created (Government of Pakistan 2013).Prior to 2005 quake, the legislature of Pakistan has constantly stressed on crisis reaction and alleviation activities. In any case, in the post 2005 quake situation the administration has put more consideration to detail master dynamic arrangements and enactments about system of management of disaster in Pakistan and how various relevant institutions can respond (Ainuddin \& Routray 2012 ). Moreover, floods 2010 were additionally one of the fundamental drivers in definition of enactment with respect to regulations about disaster management in Pakistan. Additionally, CBDM has progressively rehearsed by formative part subsequent to 2005 tremor; in spite of the fact that the effect of CBDM was extremely constrained at that spur of moment because of which floods 2010 brought on boundless misfortunes. In response to 2010 floods the legislature has given prior most importance to disaster 
management situated in community based efforts (ADPC 2003 ). CBDM guaranteed advancement and long haul recuperation of debacle influenced groups through multicompartmental methodology for example, 'cover, social, monetary framework recovery, and business revitalization' (Zimmermann \& Issa 2009 ). Case in point, the committee entrusted with the task of quick response to disastrous events- Disaster Emergency Committee-responded in a responsible and committed way by providing safe house and other facilities aimed at provision of basic life amenities in countless countryside of the province of Sindh, in addition to, improve the expectations for everyday comforts of the nearby populace against catastrophes (Murtaza et al. 2012 ). Presently the nearby groups have solid shared and precise abilities to adapt to little and substantial scale catastrophes. Essentially, Oxfam's given backing to a substantial number of individuals in Punjab territory keeping in mind the end goal to improve their readiness capacities and versatility to future catastrophes. The domestic groups of Chakhama (Kashmir) present a case for study as they were more powerless against optional risk (as avalanches) than quake. In any case, domestic groups with the support of Aga Khan Development Network has directed restricted dangers evaluations with a specific end goal to recognize seismic tremor furthermore, avalanches inclined areas. Supportability, ideal usage of inborn assets and indigenous learning as well as dynamic support of host groups are vital components in CBDM victory (Zimmermann and Issa 2009 ).The domestic individuals demonstrated their distinct fascination in completing auxiliary and non-auxiliary functions in close joint effort with common social orders as these exercises build their dependence to fiascos.

Taking into account indigenous information and past encounters, numerous towns and group based associations have created alternate courses of action for their powerless groups in Sind area. Mediations ended up succeeded when domestic groups are occupied with arranging and usage stages (Hughes 2012). Non-governmental organizations chipped away at building individuals self-reliance and associating nearby individuals with the outside on-screen characters in Sind region (Murtaza et al. 2012). Furthermore straightforwardness, responsibility and commitment of essential human rights are likewise the key variables in projects accomplishment. CBDM functions are financially savvy with high advantages. Additionally, CBDM methodology has built up a sound proficient rivalry among the executing performing artist in area of Mansehra since 2005 seismic tremor. It has made usage and surveillance simple, functional, restricted and satisfactory' to all gatherings in Mansehra. Moreover, it likewise deals with the detriments and boosters. For effective CBDM Program, building trust and affinity with nearby group is the essential prerequisite (Shah, 2013). Also CBDM procedure ought to be 'strong, agreeable also, versatile to nearby culture and framework and there will be no mystery plan. Government initiative and group proprietorship is key segments of CBDM procedure and method (Moench \& Dixit 2007). To conquer obstacles with respect to CBDM; there ought to be continuously active procedures of assembly, practicing rehearsals and transmission of abilities to the objective offices, gatherings and groups.

After 2005 seismic tremor, financial and capacity-building support of Germany set up an authority in Mansehra, Khyber Pukhtunkhwa, with the objective to respond to disaster management with the name of District Disaster Management Office Authority. The establishment was first ever particular foundation created for responding to and dealing with aftereffects of disastrous events at various levels of Pakistani society and state. In spite of the fact that assets were lacking yet it was a good example for different partners occupied with group based catastrophe administration exercises in Manshera. The mentioned office was exceptionally 
dynamic in division of obligations among concerned organizations, usage of disaster management duties and making association among practical improvement fiasco administration and compassionate activities. Furthermore program supportability and partner's abilities were constructed through sharing of learning and involvement in locale Mansehra (Shah, 2013). Disaster management, based on community efforts, at all levels is an all-inclusive approach, in which every single social gathering are incorporated (Krummacher, 2014 ).In any case, host groups are the major players to partake in this procedure (ADPC 2003 ). Inclusion of domestic groups in CBDM procedure can be conceivable through long haul promotion, appropriate group assembly and raising mindfulness among all partners. Social quality of the nearby group is extremely basic in post catastrophe stage particularly in remaking and restoration.

\section{Conclusion and Discussion:}

It is contended that 'socio-economical laborers are the experts well prepared to manage sophisticated circumstances coming about because of a crisis', because of their one of a kind parts and amplified systems in groups (Yanay \& Benjamin ,2005: 271). The part of social laborers in catastrophes is an intricate subject with different level headed discussions. Numerous contend that social specialists ought to do alleviation activities, involving utilization of their qualities to streamline the regularly clamorous situation of aftereffects of disaster for alleviation, functioning in the group and expanding approachable channel to assets for defenseless populaces. To the contrary, different scholars concentrate on the significance of social specialists in agonizing stretch and questioning administrations. Are social laborers fit for filling the part of supporters and coordinators? Is the calling intrigued by such a part for social laborers? It can be safely said that for the most part we are not as of now prepared for on the other hand focused on such parts. A noteworthy movement in social work instruction would be vital. The part of questioning and injury decrease is imperative.

Be that as it may, Specht and Courtney (1996) suggests that one must ask what proof we have that this is the thing that groups truly require most. By centering our vitality on anxiety questioning and introspecting the anxiety-related issues after the traumatic phase, are we propagating unfairness by disregarding the bigger improvement problems? Are we simply indulging ourselves into fruitless war without sorting out the ways to avoid and pre-empt the war? It can be accepted that analysts cal lead a great part of the emotional wellness work, excluding socio-cultural laborers to concentrate on administrative interaction and post-catastrophe arranging and advancement. Else, we may fall short of understanding the expert goals of social and monetary equity by disregarding basic socio-economic improvement. On the off chance that catastrophes uncover long-existing improvement issues, then it appears that catastrophe recuperation should concentrate on tending to these fundamental improvement issues, similar to neediness and bigotry. However social work tends to concentrate on expanding mental working on the other hand expanding access to administrations. While recuperating and benefit procurement are key with regards to disasters, such exercises don't as a matter of course address social change. A typical emotional wellness system utilized as a part of debacle circumstancesCritical incident stress debriefing(CISD), was produced initially as an approach to rapidly return troopers to fight (Mitchell, 1983). This reasoning does not appear to be similar with the help of social and financial equity. Despite the fact that a few regions of calamity practice are centered around the material prosperity also, interpersonal organizations of post-disaster rehabilitation, an equity centered arrangement stays slippery. 


\section{References}

ADPC. (2003).CBDRM-11 course reference manual. Asian Disaster Preparedness Centre, Bangkok.

Ainuddin S. \& Routray J. K. (2012). Institutional framework, key stakeholders and community preparedness for earthquake induced disaster management in Balochistan. Disaster J Prevention Management. 21(1):22-36

Alinsky, S. (1971). Rules for Radicals: A Practical Primer for Realistic Radicals. New York: Vintage.

Allen, K. (2003) 'Vulnerability Reduction and the Community-based Approach: A Philippines Study', in M. Pelling (ed.) Natural Disasters and Development in a Globalizing World, pp. 17084. London: Routledge.

Axel-Lute, M. (2006). Picking Up the Pieces. Shelterforce Online, 145. Available online at: www.nhi.org/online/issues/145/pickinguppieces.html (accessed 30 June 2016).

Chambers, R. (1994). Participatory Rural Appraisal (PRA): Analysis and Experience. World Development 22(9): 1253-68.

Fisher, R. (1994). Let the People Decide: Neighborhood Organizing in America. New York: Twayne Publishers.

Galambos, C.M. (2005). Natural Disasters: Health and Mental Health Considerations', Health and Social Work 30(2): 83-6.

Government of Pakistan (2013). National disaster risk reduction policy. National Disaster Management Authority, Islamabad.

Harrell, E.B. \& Zakour, M. J. (2000). Including Informal Organizations in Disaster Planning: Development of a Range-of-Type Measure. Tulane Studies in Social Welfare 21(2): 61-83.

Holzer, H.J. \& Lerman, R.I. (2006). Employment Issues and Challenges in PostKatrina New Orleans', in M.A. Turner \& S.R. Zedlewski (eds) After Katrina: Rebuilding Opportunity and Equity into the New New Orleans. Washington, DC: Urban Institute. Available online at: http://www.urban.org/UploadedPDF/ 900921_employment_issues.pdf

Hughes, K. (2012). Effectiveness review: community-based disaster risk management and livelihoods programme, Pakistan: Full Technical Report. Retrieved from http://oxfamilibrary. openrepository.com/oxfam/bitstream/10546/247231/3/er-drr-pakistan-effectiveness-review081012-full-report-en.pdf

Krummacher, A. (2014). Community Based Disaster Risk Management (CBDRM) . Paper presented at the responding to environmental challenges with a view to promoting cooperation and security in the OSCE area, Vienna

Low, S.M., Taplin, D.H. \& Lamb, M. (2005). Battery Park City: An Ethnographic Field Study of the Community Impact of 9/11, Urban Affairs Review 40(5): 655-82.

McNeil, M., Goddard, J., Henderson, A., Phelan, M., Davis, S. Wolkin, A. \& Batts, D. (2006). 'Rapid Community Needs Assessment after Hurricane Katrina - Hancock County, Mississippi, 14-15 September 2005', Morbidity and Mortality Weekly Report 55(9): 234-6

Moench, M., \& Dixit, A. (eds).(2007).Working with the winds of change: towards strategies for responding to the risks associated with climate change and other hazards. Institute for Social and Environmental Transition, ProVention, Kathmandu

Mohan, G. \& Stokke, K. (2000). Participatory Development and Empowerment: The Dangers of Localism', Third World Quarterly 21(2): 247-68. 
Morrow, B.H. \& Peacock, W.G. (1997). Disasters and Social Change: Hurricane Andrew and the Reshaping of Miami?', in W.G. Peacock, B.H. Morrow and H. Gladwin (eds) Hurricane Andrew: Ethnicity, Gender and the Sociology of Disasters, pp. 226-42. New York: Routledge.

Mitchell, J. (1983).When Disaster Strikes: The Critical Incident Stress Debriefing Procedure', Journal of Emergency Medical Service 8(1): 36-9.

Murphy, P.W. and J.V. Cunningham (2003) Organizing for Community Controlled Development: Renewing Civil Society. Thousand Oaks, CA: Sage.

Murtaza, N., Alam, K., \& Bhatti, S. (2012). Disaster risk reduction in Pakistan: the contribution of DEC member agencies, 2010-2012. Retrieved from http://www.dec.org.uk/sites/default/fi les/fi les/ Evaluations/Pakistan/DEC\%20Pakistan\%20DRR\%20Report.pdf

Shah, S. H .(2013). The disaster risk management handbook. A learning experience of DRM Model Mansehra. Retrieved from http://www.preventionweb.net/fi les/32968_32968buildingresilience bylearningth.pdf

Sundet, P. \& Mermelstein, J. (1996). Predictors of Rural Community Survival after a Natural Disaster: Implications for Social Work Practice', in C.L. Streeter and S.A. Murty (eds) Research on Social Work and Disasters, pp. 57-70. Binghamton, NY: Haworth Press.

Ozerdem, A. (2003). Disaster as Manifestation of Unresolved Development Challenges: The Marmara Earthquake, Turkey', in M. Pelling (ed.) Natural Disasters and Development in a Globalizing World, pp. 199-213. London: Routledge.

Robards, K.J., Gillespie, D.F. \& Murty, S.A. (2000). Clarifying Coordination for Disaster Planning', in M.J. Zakour (ed.) Disaster and Traumatic Stress Research and Intervention, pp. 4160. New Orleans, LA: Tulane Studies in Social Welfare.

Specht, H. \& Courtney, M. E. (1996). Unfaithful Angels: How Social Work Has Abandoned Its Mission. New York: The Free Press. Sundet, P. and J. Mermelstein (1996) 'Predictors of Rural Community Survival after a Natural Disaster: Implications for Social Work Practice', in C.L. Streeter and S.A. Murty (eds) Research on Social Work and Disasters, pp. 57-70. Binghamton, NY: Haworth Press.

Van den Eynde, J. \& Veno, A. (1999). Coping with Disastrous Events: An Empowerment Model of Community Healing, in R. Gist and B. Lubin (eds) Responses to Disaster: Psychosocial, Community and Ecological Approaches, pp. 167-92. Philadelphia, PA: Taylor \& Francis.

Vandeventer, P. (2004). From Chaos to Community: A Guide to Helping Friends and Neighbors Recover and Rebuild After a Major Disaster. Los Angeles, CA: Community Partners

Victoria, L.P. (2001) 'Community-based Approaches to Disaster Mitigation'. Available online at: www.unpan1.un.org/intradoc/groups/public/documents/APCITY/ UNPAN009661.pdf (accessed 30 June 2006)

Yanay, U. \& Benjamin, S. (2005). The Role of Social Workers in Natural Disasters: The Jerusalem Experience. International Social Work 48(3): 263-76.

Zakour, M.J. (1996). Disaster Research in Social Work in C.L. Streeter and S.A. Murty (eds) Research on Social Work and Disasters, pp. 7-25. Binghamton, NY: Haworth Press

Zedlewski, S.R. (2006). Building a Better Safety Net for the New New Orleans in M.A. Turner and S.R. Zedlewski (eds) After Katrina: Rebuilding Opportunity and Equity into the New New Orleans. Washington, DC: Urban Institute. Available online at: http://www.urban.org/UploadedPDF/900922_safety_net.pdf

Zimmermann, M. N., \& Issa, S. S. (2009). Risk-conscious reconstruction in Pakistan administered Kashmir. Mt Res Dev 29(3):202-210 